\title{
Ensino de história, planejamento e autoria: experimentações com literatura negra em estágios curriculares obrigatórios
}

\author{
Teaching history, planning and authorship: experiments with black literature in \\ compulsory curricular stages
}

\begin{abstract}
Carla Beatriz Meinerz
Doutora em Educação pela Universidade Federal do Rio Grande do Sul. Docente do Programa de Pós-Graduação em Educação da Faculdade de Educação da Universidade Federal do Rio Grande do Sul. Rio Grande do Sul - RS - Brasil carlameinerz@gmail.com

Fernanda Amorin Golembiewski Especialista em Ensino de História e Geografia pela Universidade Federal do Rio Grande do Sul. Rio Grande do Sul - RS - Brasil fernanda.golembiewski@ufrgs.br

Raisa da Silva Oyarzabal Especialista em Ensino de História e Geografia pela Universidade Federal do Rio Grande do Sul. Rio Grande do Sul - RS - Brasil raisa.oyarzabal@ufrgs.br
\end{abstract}

\begin{abstract}
Resumo: Objetiva analisar a autoria do professor de história na criação de aulas, através da construção de planejamentos conectados com literaturas, histórias e culturas africanas e negras. Resulta de reflexões a partir de práticas metodológicas de ensino e pesquisa com documentos de estágios curriculares obrigatórios do curso de Licenciatura em História da UFRGS. Problematiza a presença étnico-racial hegemônica nos saberes expressos nesses planejamentos. Como referência no campo específico do ensino de História, utiliza a autora Ana Maria Ferreira da Costa Monteiro e, no campo geral da Educação e formação de professores, o autor Maurice Tardiff. No campo da literatura, fundamenta-se nos escritos do pensador Luiz Silva (Cuti). Os resultados parciais apontam a recorrência do uso de narrativas históricas e literárias vinculadas aos conteúdos de história e cultura africana e afro-brasileira, com menos enunciação do diálogo entre saberes distintos e da educação das relações étnico-raciais.
\end{abstract}

Palavras-chave: Ensino de História. Literatura. Planejamento. Autoria. Estágios Curriculares Obrigatórios.

\begin{abstract}
It aims to analyze the authorship of the history teacher in the creation of classes, through the construction of plans connected with black and African literatures, histories and cultures. It results from reflections from methodological practices of teaching and research with documents of compulsory curricular internships of the course of Degree in History of UFRGS. It problematizes the hegemonic ethnic-racial presence in the knowledge expressed in these plans. As a reference in the specific field of teaching History uses the author Ana Maria Ferreira da Costa Monteiro and, in the general field of
\end{abstract}


Education and teacher training, the author Maurice Tardiff. In the field of literature it is based on the writings of the thinker Luiz Silva (Cuti). The partial results point to the recurrence of the use of historical and literary narratives linked to the contents of African and Afro-Brazilian history and culture, with less enunciation of the dialogue between distinct knowledge and the education of ethnic-racial relations.

Keywords: History Teaching. Literature. Planning. Authorship. Compulsory Curricular Internships.

\section{Considerações Iniciais acerca da presença das temáticas negras nas aulas de história}

Começamos nossa escrita com um trecho do conto "Boneca" de Luiz Silva (Cuti) (2016, p. 44):

\footnotetext{
Não. Por gentileza, eu estou procurando uma boneca...

Temos várias. Olha aqui a Barby, a Xuxinha... E a loirinha foi apanhando diversas bonecas. Colocava-as sobre o balcão, como se escolhesse para si. Olha que gracinha esta aqui de olhos azuis! É novidade. Chegou ontem e já vendeu quase tudo. Chora, tem chupeta, faz pipi... E essa outra aqui? Não é uma graça? E levou ao colo a ruivinha de tom amarelado, bem clarinha. Mexeu-lhe os bracinhos e as perninhas e indagou: Não gostou de nenbuma?

É que estou procurando uma boneca negra...

Tem sim! - o dono da loja dirigia-se à empregada: Procura melhor, na prateleira de baixo, lá em cima mesmo, perto da pia.
}

Inspirando-nos na metáfora literária que conta a trajetória de um pai em busca de uma boneca negra para presentear sua filha nos festejos natalinos, indagamos sobre a presença das temáticas negras nas aulas de história. Vamos contar trajetórias de buscas da presença negra nos planos de jovens professores em formação, inquiridos a tratar de educação das relações étnicoraciais em suas aulas. A partir de reflexões construídas em análise de experimentações realizadas nos estágios curriculares obrigatórios do curso de Licenciatura em História da Universidade Federal do Rio Grande do Sul (UFRGS), tratamos da importância da autoria do professor de história no momento de criar suas aulas, por meio de planejamentos com uma perspectiva participativa, interativa e emancipatória. A pergunta central de nossa escrita é: Qual a presença étnico-racial hegemônica nos saberes expressos nesses planejamentos?

Nosso foco analítico centra-se na relação pedagógica interativa, dialógica e emancipatória (FREIRE, 1996), considera o protagonismo do jovem estudante na relação com os diferentes saberes que circulam no processo de aprendizagem (CHARLOT, 2000). O jovem estudante é compreendido em seu lugar válido de fala dentro desse processo dialógico, interlocutor ativo na 
negociação de saberes históricos (MONTEIRO; PENNA, 2011). Buscamos compreender as escolhas epistemológicas que destacam o protagonismo de pensadores negros nos planos dos professores estagiários, a partir do que aprendemos com os saberes construídos nas lutas por emancipação, forjadas pelo movimento negro educador no Brasil (GOMES, 2017). Tais aprendizagens levam à descolonização dos currículos (GOMES, 2012), demarcada pelos marcos legais instaurados a partir da Lei 10.639/03, que institui a obrigatoriedade do ensino de histórias e culturas negras e afro-brasileiras na educação nacional.

O presente estudo se coloca na perspectiva que Nilma Lino Gomes (2017), inspirada na sociologia proposta por Boaventura de Sousa Santos, nomeia como pedagogia das emergências: aquelas que reconhecem e tornam credíveis os saberes produzidos, articulados e sistematizados pelo movimento negro para a prática e para o pensamento educacional. Observa a relação dessa formulação com as pedagogias decoloniais, nascidas das lutas, resistências e práticas insurgentes (WALSH, 2013). As pedagogias das emergências criam a tensão necessária para o rompimento das pedagogias das ausências (GOMES, 2017), aquelas que produzem intencionalmente o ausente, o não existente, o não credível. Trata-se, nesta análise, de destacar as ausências e permanências da educação das relações étnico-raciais nos planos e práticas docentes relativas aos estágios curriculares obrigatórios de ensino de história. Enfocamos a interação com saberes diversos, buscando na literatura negro-brasileira (SILVA, 2010), e no diálogo com os movimentos sociais, a fundamentação para práticas conectadas com uma história plural e uma ecologia de saberes (SANTOS, 2010).

A literatura negro-brasileira, segundo Silva (2010), marca a presença de personagens, autores e leitores negros e negras, creditando e valorizando positivamente os saberes dos sujeitos da diáspora africana no Brasil. Para o autor, "a literatura é poder, poder de convencimento, de alimentar o imaginário, fonte inspiradora do pensamento e da ação.” (p. 12). Como fazer humano e plural, ela experimenta o racismo e a luta antirracista em seu processo. No caso de nosso país, a produção literária negro-brasileira anuncia saberes que se expressam no "entrechoque das ideias e nos intercâmbios dos pontos de vista." (p. 13).

As narrativas literárias e históricas, na qualidade de conhecimentos sistematizados e relacionados aos currículos e ao ensino escolarizado, são práticas socioculturais mediadas pela linguagem e constituídas em relações de poder. Roland Barthes (1989), no clássico texto "Aula", ao argumentar acerca do fato de que a liberdade existe somente fora da linguagem, pergunta-se sobre o que, então, permitiria driblá-la, já que a linguagem não possui exterioridade. A resposta 
do pensador está na literatura, na escrita e no texto. Assim, "linguagem, em seu aspecto de aprisionamento, é combatida não pela mensagem de que ela é instrumento, mas pelo jogo de palavras de que ela é teatro (p. 17). Jogar com as palavras parece fundamental na relação pedagógica. Esse jogo pode ser intencionalmente pensado, através das escolhas epistêmicas realizadas nos textos dos planejamentos do educador.

A escrita que ora apresentamos surge como fruto das reflexões acerca das práticas docentes nos estágios de duas licenciandas que, no momento da escrita, atuavam como monitoras das atividades de ensino de Estágio de Docência em História I - Ensino Fundamental. Resulta igualmente de diálogos com uma docente universitária, responsável pelas atividades de ensino dos estágios curriculares obrigatórios de História. Conecta-se com resultados de pesquisa com base em análise documental produzida em relatórios de estágio. O recorte temporal da análise é circunscrito aos anos de 2013 e 2014, tendo como referência a metodologia que cruza relatos de experiências de estágio e monitoria em atividades de ensino em história, assim como a análise de relatórios de um grupo de professores em formação. $\mathrm{Na}$ análise documental qualitativa, compreende-se a produção de dados num conjunto de 48 relatórios de estágio, correspondendo aos estágios de ensino fundamental, realizados no segundo semestre de 2013.

\section{Planejamento como Processo Criativo: entre o protagonismo do estudante e a autoria do professor}

No curso de licenciatura em história da UFRGS, as atividades de ensino vinculadas à docência e aos estágios curriculares são realizadas na Faculdade de Educação, momento em que o licenciando é convocado a elaborar uma trajetória de ações e reflexões conectadas com suas vivências no espaço escolar, colocando-se como autor e criador de suas proposições políticopedagógicas. São ações obrigatórias dessas atividades: 1) a observação do espaço escolar e da turma em que será realizada a prática docente, através de aproximações com os diferentes atores da comunidade escolar; 2) a construção de um diagnóstico inicial com o perfil da turma, geralmente através de um questionário ou enquete realizado nos primeiros encontros com os estudantes; 3) a confecção de um plano geral, a partir de recortes teórico-metodológicos no campo da História e da Educação, evidenciando a busca por um foco temático para a prática docente realizada no acordo $^{1}$ com a escola, o professor de História e o orientador do estágio; 4) a 
confecção de planos específicos e de materiais didáticos próprios criados em processos de autoria e pesquisa; 5) a constante avaliação dos impactos das práticas propostas e possível reorientação das escolhas didáticas; 6) a visita de supervisão do estágio, acompanhada por um retorno ao licenciando sobre esse momento de observação; 7) a avaliação do estágio por parte dos jovens estudantes da escola; 8) a construção dos textos reflexivos finais: para o ensino fundamental trata-se de um relatório e, para o ensino médio, um artigo.

Em nossas experiências docentes buscamos construir os planejamentos valorizando o conceito de autoria e as possibilidades que ele pode propiciar para as aulas de história. A autoria dos recursos didáticos, que implica em escolhas feitas pelo professor, é entendida como uma potencialidade, na medida em que permite a construção de planejamentos para realidades específicas de turmas. Nesse sentido, é possível estabelecer um vínculo entre a autoria do professor e o protagonismo do estudante, mediadas pelos diálogos com literaturas diversas, capazes de consolidar uma ecologia de saberes (SANTOS, 2010).

A confecção de materiais didáticos de autoria do professor estagiário constitui uma das etapas importantes do estágio docente. Esses materiais devem ser elaborados a partir dos diagnósticos obtidos nas observações. Construir um material didático é um dos desafios da prática docente, pois torna necessário que o professor em formação saia da zona de conforto e do que está acostumado na rotina acadêmica - ou seja, textos longos e nem sempre didáticos - e pense em recursos adequados aos jovens da educação básica.

Os relatórios dos estágios, portanto, objetivam uma escrita que se constitui em um modo radical de expressar o pensamento reflexivo. Ela se torna uma expressão narrativa forte, pois através dela é possível avaliar, julgar, compreender e redimensionar os fatos e experimentações próprias do estágio, ao considerar uma relação do licenciando consigo mesmo - suas escolhas, impulsos, atitudes, omissões, alegrias e dúvidas. Tal expressão narrativa conecta-se com o jogo de tentativas de driblar os aprisionamentos que a própria linguagem nos coloca, conforme Roland Barthes (1989). Esse processo é constituído por intensos encontros e diálogos, entre os colegas em aulas presenciais, entre o supervisor e o estagiário em orientações individuais, entre os monitores e os estagiários em momentos virtuais ou presenciais. Nessa interação desenvolve-se a autoria docente.

Entendemos por autoria do professor, mesmo daquele em formação inicial, toda a ação que exija a opção por metodologias e teorias, o desenvolvimento dos próprios materiais didáticos, a seleção das abordagens historiográficas e dos recortes temáticos. Ressaltamos a estreita relação 
entre a ideia de protagonismo do estudante e de autoria do professor, por entendermos que o exercício da autoria nos permite construir propostas de ensino a partir da realidade que se apresenta na sala de aula e do conhecimento das turmas para as quais essas propostas são pensadas. Nesse sentido, nossa contribuição para a área de ensino de história é reafirmar que a prática docente não é vazia de teoria, e que o professor possui um saber específico - o saber docente. Sobretudo, não é vazia de opções políticas e pedagógicas. Ao escolher, por exemplo, uma literatura negro-brasileira (SILVA, 2010), o professor opta por saberes construídos pelos negros e não sobre os negros, apostando na sua emancipação e valorização.

Para Tardiff \& Lessard (2011), o sentido do trabalho do professor não pode ser construído independentemente dos outros atores do cotidiano com os quais trabalham os docentes, no caso, os alunos. Nessa perspectiva, fundamentamos a ideia de autoria docente e protagonismo estudantil. É preciso levar em conta a pluralidade das experimentações dos jovens alunos, buscando conhecer seus pertencimentos comunitários, familiares, grupais, religiosos, igualmente as relações de classe, de gênero e étnico-raciais em que estão envolvidos. Por vezes, nessa interação acabamos por construir espécies de acordos entre mundos distintos, entre saberes diferenciados. É nessa negociação (MONTEIRO; PENNA, 2011) entre os saberes próprios dos jovens e os saberes específicos dos professores que está a habilidade própria do docente.

O planejamento em educação é uma temática que envolve diferentes concepções e abordagens. Entendemos aqui o planejamento como processo de autoria e criatividade que pressupõe escolhas permeadas pelas opções teóricas e metodológicas de seus proponentes. No caso do ensino de história, são escolhas no campo da História e no campo da Educação. Para Monteiro e Penna (2011), o ensino de história deve ser pensado como um "lugar de fronteira", utilizando-se de referenciais e conceitos desses dois campos. Nesse aspecto, não pensamos mais a partir da tradição cartesiana do método, constituída no contexto do pensamento moderno, em que planejar era praticar e organizar técnicas para alcançar resultados exatos: um bom plano, com boas técnicas, resultaria no alcance de bons resultados. Isso não significa negar o valor de ações planejadas e contextualizadas, em que teoria e prática são indissociáveis. Não se trata mais de construir e depois usar um bom plano ou um bom método, e sim de decidir ou selecionar teorias e metodologias, dentro de um contexto de produção cultural e de relação político-pedagógica. 


\section{A Autoria Docente e o Protagonismo dos Alunos nas Experiências de Estágios Obrigatórios}

Para Tardiff e Lessard (2011), o ensino escolar vem desempenhando historicamente o papel de filtro entre a sociedade e a cultura, por um lado, e as jovens gerações, por outro lado. Esse desempenho tem sido parte do que representa a especificidade do ofício do professor. Porém, na atualidade, para os autores,

O que é novo é a aceleração da transformação, tanto da sociedade quanto da cultura, o que torna a função da escola certamente tão importante quanto foi outrora, e até mais, porque ela atinge todos os membros de uma geração e por mais tempo do que outrora, porém mais arriscada e difícil para os docentes, porque os materiais de construção do trabalho são menos garantidos do que antes. (LESSARD; TARDIFF, 2011, p. 277).

Sabemos que as condições de trabalho da maioria dos professores no Brasil não garantem, em termos salariais, pedagógicos, temporais, espaciais e infraestruturais, o exercício do ofício de maneira qualificada e capaz de atender às exigências da contemporaneidade. No entanto, nossa escrita parte da premissa de que o momento do estágio curricular obrigatório tende ainda a criar ambientes e exigências capazes de construir práticas qualificadas e "inéditos viáveis" (FREIRE, 1996). Apontamos então para o que seja possível. A partir deste momento, sistematizamos dois relatos de práticas docentes de ensino de História na Educação Básica, constituídas nesse processo de estágio, cujo foco é o desejo de construir autoria do professor e protagonismo do aluno. A seguir, construiremos apontamentos parciais sobre eles, na conexão com análise documental de planejamentos de 48 relatórios de estágio.

Relato Primeiro²: Realizei as minhas duas práticas de estágio na minha cidade - Viamão -, que fica na região metropolitana de Porto Alegre, em turmas distintas, uma delas na Educação de Jovens e Adultos. Destaco aqui o quão importantes foram as doze horas de observação para entender o funcionamento da escola, bem como o andamento e o desempenho das turmas. Mas, além da observação, foi fundamental para a construção do planejamento a aplicação de um questionário individual. Este planejamento não foi livre, mas adaptado ao que foi pedido pelo professor titular, com centralidade na narrativa histórica centrada na Europa. Os planejamentos foram construídos a partir das especificidades de cada turma, sempre trazendo o aluno para o 
protagonismo das aulas. Foi desafio do planejamento deste estágio (re)construir parte do conhecimento histórico dos alunos, trazendo narrativas de cultura e história africana e afrobrasileira.

Relato Segundo ${ }^{3}$ : Minhas duas experiências de estágio tiveram em comum a escolha da mesma temática como central nos planejamentos: a História da África. O objetivo dessa escolha justificou-se a partir da Lei 10.639/03 e da intenção de atuar na construção de relações étnicoraciais baseadas no respeito à diversidade e no combate ao racismo. Nos dois planejamentos, a primeira unidade de trabalho trouxe questionamentos a respeito dos saberes dos alunos sobre a África e acerca do ensino da história desse continente - buscando compreender de que forma ele está sendo (ou não) contemplado nas escolas. A autoria foi priorizada nos dois estágios docentes, apresentando-se como um recurso importante para possibilitar a participação e o protagonismo dos estudantes nas aulas. Os materiais elaborados incluíram textos didáticos, mapas do continente africano, exibição de vídeos e proposição de roteiros de análise para os mesmos. A utilização de questionários aplicados no início dos estágios, mencionada anteriormente como uma ferramenta para pensar na relação entre autoria do professor e protagonismo do estudante, foi uma importante ferramenta utilizada nas experiências desse relato. Uma das questões proposta aos alunos no questionário foi “o que você conhece sobre a África e sua história?”. A partir da pergunta, foi possível analisar, antes de iniciar a discussão sobre o assunto, os saberes dos estudantes a respeito do tema, subsidiando as futuras discussões que seriam construídas ao longo do estágio. O uso de poemas e narrativas literárias sobre a África gerou importantes evocadores de memória para a construção de conhecimentos.

Sintese de palavras-chave encontradas em escritas de relatórios de práticas docentes: ao buscar palavraschave nas narrativas dos estagiários de 2013/2, referentes a temas de histórias e de culturas africanas e afro-brasileiras, ao conceito de educação das relações étnico-raciais ou à legislação, encontramos os seguintes resultados ou incidência das mesmas: cultura afro-brasileira (5), reinos africanos (3), escravidão (2), educação para a diversidade (2), história da África (1), Lei no 10.639/03 (1), consciência negra (1), Educação das Relações Étnico-Raciais (1), Preconceito e discriminação (1), resistência negra (1), tráfico de escravos (1), questões étnico-raciais (1), quilombos (1), reinos africanos (1), África (1), Zumbi dos Palmares (1). O uso de textos literários ou de autores referenciados como negros ainda é minoritário em relação ao uso de fontes historiográficas e de livros didáticos. Em relação aos planejamentos de ensino, observou-se a inclusão de temas referentes à Lei $n^{\circ}$ 10.639/03 (BRASIL, 2003) ou às propostas das Diretrižes 
(BRASIL, 2004), em 18 exemplos, no conjunto total de 48 planejamentos componentes dos relatórios de estágio. Nos demais, ou seja, em 30 planejamentos, não se observou a inclusão desses temas e/ou propostas. Na análise dos planejamentos de ensino, associada aos demais materiais componentes dos relatórios de estágio, observou-se a inclusão de temas relativos à: história africana; história dos afro-brasileiros; cultura africana; cultura afro-brasileira.

\section{Considerações Parciais}

Qual a presença étnico-racial hegemônica nos saberes expressos nessas práticas de ensino e nesses planejamentos? Os resultados parciais apontam a pequena recorrência do uso de narrativas históricas e literárias vinculadas aos conteúdos de história e cultura africana e afrobrasileira, com menos enunciação do diálogo entre saberes distintos e da educação das relações étnico-raciais. $\mathrm{Na}$ proposta desta análise, os planejamentos configuram-se como o que nomeamos de pedagogia das ausências (GOMES, 2017). Observamos que o conceito pedagogia das emergências.

Segundo pesquisadoras que tratam das produções nessa área, como Selva Guimarães Fonseca (1995; 1997) e Flavia Eloísa Caimi (2001; 2008), convivemos com uma diversidade de maneiras de pensar e de fazer o ensino de história. Caimi (2008) faz uma imersão investigativa nas memórias e relatos de estagiários de cursos de licenciatura em História durante a realização de suas práticas docentes, propondo a superação do caráter técnico-instrumental, que é tradicionalmente atribuído aos estágios dessa natureza, e assumindo a reflexão teóricometodológica como instância cognitivo-explicativa do trabalho docente. Em estudo sobre o modo pelo qual os professores de história mobilizam seus saberes na prática docente, Monteiro (2007) também observa que o significado da docência se relaciona com o compromisso da formação de cidadãos críticos. Monteiro sugere que esta seja "uma característica da identidade profissional dos professores de História, este compromisso com a dimensão formadora do ensino" (MONTEIRO, 2007, p. 66). Tal perspectiva relaciona-se com a experiência de vida de cada sujeito.

No caso do uso de narrativas históricas e literárias construídas por meio do protagonismo das epistemologias negro-brasileiras, observa-se, como resultados dos dados aqui analisados, uma tensão entre ausências e emergências (GOMES, 2017). 
Nossas experiências docentes - diferentes entre si e igualmente enriquecedoras - nos mostram que a escolha pela autoria apresenta muitas potencialidades ao professor de História, como uma ferramenta transformadora em suas aulas, pois possibilita que seus alunos sejam sujeitos protagonistas na construção do seu conhecimento, já que seus saberes e vivências são considerados na construção dos planejamentos. Essa autoria pressupõe opções políticopedagógicas, capazes de reiterar a pedagogia das ausências ou evocar a pedagogia das emergências. $\mathrm{Na}$ qualidade de emergentes estão os saberes emancipatórios construídos historicamente nas lutas das pessoas negras no Brasil, representadas por importantes intelectuais, poetas, contistas.

Nossa proposta construiu um olhar direcionado às escolhas teórico-metodológicas e às formas como se inserem, em planejamentos ou em currículos, a complexidade dos processos históricos. Desse modo, foi possível apenas anunciar a compreensão das apropriações das obrigatoriedades legais pelos sujeitos envolvidos na educação.

Concluímos com a inquietação de que a busca da aplicação desses marcos legais, constituídos a partir da Lei 10.639/03, ainda tem por premissa hegemônica um lugar de fala que trata do outro e não com o outro, trata antes das narrativas e literaturas sobre os negros do que pelos negros e com os negros. Uma dialogia emancipatória, por nós defendida, aposta no diálogo e na interação entre diversos sujeitos e saberes como um caminho para a educação das relações étnico-raciais.

\section{Notas}

${ }^{1} \mathrm{O}$ planejamento pensado como um acordo pressupõe uma negociação entre as partes já referidas. Nesse caso, não há plena autonomia no exercício da autoria na construção do planejamento. O planejamento muitas vezes é uma negociação que acaba não proporcionando a livre autoria em todas as suas possibilidades e sim uma autoria limitada.

${ }^{2} \mathrm{O}$ relato é feito na primeira pessoa do singular para evidenciar a autoria da licencianda.

3 O relato é feito na primeira pessoa do singular para evidenciar a autoria da licencianda. 


\section{Referências}

BARTHES, Roland. Aula. São Paulo: Editora Cultrix, 1989.

BRASIL. Lei n. 10.639 de 09 de Janeiro de 2003. Altera a Lei no 9.394, de 20 de dezembro de 1996, que estabelece as diretrizes e bases da educação nacional, para incluir no currículo oficial da Rede de Ensino a obrigatoriedade da temática "História e Cultura Afro-Brasileira", e dá outras providências. Diário Oficial da União, Brasília, DF, 10 jan. 2003.

BRASIL. Ministério da Educação/SECAD/SEPPIR. Diretrizes Curriculares Nacionais para a Educação das Relações Étnico-Raciais e para o Ensino de História e Cultura Afro-Brasileira e Africana.

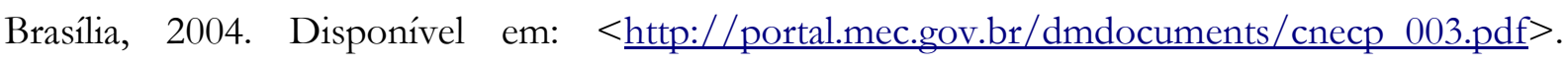
Acesso em: 22 nov. 2018.

CAIMI, Flávia Eloisa. Conversas e Controvérsias: o ensino de história no Brasil (1980-1998). Passo Fundo: UPF, 2001.

CAIMI, Flávia Eloisa. Aprendendo a ser professor de História. Passo Fundo: Editora da Universidade de Passo Fundo, 2008. 306 p.

CHARLOT, Bernard. Da relação com o saber, elementos para uma teoria. Porto Alegre: ARTMED, 2000.

FONSECA, Selva Guimarães. Caminhos da história ensinada. Campinas: Papirus, 1995.

FONSECA, Selva Guimarães. Serprofessor no Brasil: história oral de vida. Campinas: Papirus, 1997.

FREIRE, Paulo. Pedagogia da autonomia. São Paulo: Paz e Terra, 1996.

GOMES, Nilma Lino. Relações étnico-raciais, educação e descolonização dos currículos. Currículo sem Fronteiras, v. 12, n. 1, p. 98-109, jan./abr. 2012. 
GOMES, Nilma Lino. O movimento Negro Educador: saberes construídos nas lutas por emancipação. Petrópolis: Vozes, 2017.

MONTEIRO, Ana Maria. Professores de História: entre saberes e práticas. Rio de Janeiro: Mauadx, 2007.

MONTEIRO, Ana Maria Ferreira da Costa; PENNA, Fernando de Araujo. Ensino de história: saberes em lugar de fronteira. Educação e Realidade, Porto Alegre, v. 36, n. 1, p. 191-211, 2011. Disponível em: <http://seer.ufrgs.br/index.php/educacaoerealidade/article/view/15080>. Acesso em: 18 nov. 2015.

SANTOS, Boaventura de Sousa. Para além do pensamento abissal: das linhas globais a uma ecologia de saberes. In: SANTOS, Boaventura de Sousa; MENESES, Maria Paula. Epistemologias do Sul. São Paulo: Cortez, 2010. p. 23-71.

SILVA, Luiz (CUTI). Literatura negro-brasileira. São Paulo: Selo Negro Edições, 2010.

SILVA, Luiz (CUTI). Contos Escolbidos/Cuti. Rio de janeiro: Malê, 2016.

TARDIFF, Maurice; LESSARD, Claude. O oficio do professor: história, perspectivas e desafios internacionais. Petrópolis, RJ: Editora Vozes, 2011.

WALSH, C. Introducción. Lo pedagógico y lo decolonial: entretejiendo caminhos. In:

Pedagógias decoloniales: prácticas insurgentes de resistir, (re) existir y (re) vivir. Tomo I. Serie Pensamiento Decolonial. Quito, Ecuador, noviembre 2013. p. 23-68.

recebido em 29 set. 2018 / aprovado em 21 nov. 2018

Para referenciar este texto:

MEINERZ, C. B.; GOLEMBIEWSKI, F. A.; OYARZABAL, R. S. Ensino de História, Planejamento e Autoria: experimentações com literatura negra em estágios curriculares obrigatórios. Dialogia, São Paulo, n. 30, p. 59-70, set. /dez. 2018. Disponível em: $<$ https://doi.org/10.5585/Dialogia.n30.10617> 